\title{
Evolução histórica e filosófica do conceito de nível de base fluvial
}

\author{
Cláudio Eduardo Lana \\ Universidade Federal do Espírito Santo, Depto. Geologia \\ claudiolana@ufes.br \\ Paulo de Tarso Amorim Castro \\ Universidade Federal de Ouro Preto,Depto. Geologia \\ paulo_de_tarso@degeo.ufop.br
}

\begin{abstract}
Historical and philosophical evolution of the concept of river base level: Literature revision of the conceptual evolution of fluvial base levels is presented herein. Specialized publications show that there is a long term relationship between the human society and the fluvial morphological flats. For this reason different meanings of a base level were postulated along the last centuries. Each conception is a clear evidence of the invigorating philosophical pattern at a specific time. Moreover, the succession of different conceptions point to the improving human comprehension of nature. This work is composed of two main sections. First a synthesis of the philosophical and historical evolution stages of the base level concept is presented. Thereafter the different meanings of this term are discussed as well as their correct usage.
\end{abstract}

KEYWORDS: Base level, conceptual evolution, historical evolution.

RESUMO Este trabalho apresenta uma revisão bibliográfica acerca da evolução do conceito de nível de base fluvial. A literatura especializada mostra que, ao longo de sua existência, o Homem tem estabelecido uma relação direta com os patamares morfológicos desenvolvidos às margens dos rios. Com isso, uma série de concepções a respeito do significado dos mesmos se com o com o tempo, cada uma delas traduzindo o padrão filosófico de sua época e a consequente capacidade humana de percepção dos fenômenos naturais. O trabalho é dividido em duas partes principais: a primeira sintetiza as etapas da evolução histórica e filosófica do conceito de nível de base, enquanto a segunda se dedica aos diferentes significados que são atribuídos ao termo e à discussão da aplicabilidade de cada um deles.

PALAVRAS-CHAVE: Nivel de base, evolução conceitual, evolução histórica.

\section{1 - Introdução}

Uma rápida consulta à literatura especializada em Geomorfologia, Sedimentologia e demais áreas afins mostra que o significado atual de "nível de base fluvial" não é uma unanimidade, estando relacionado estreitamente ao foco de cada publicação consultada.

Quando se leva em conta a realização de uma consulta semelhante, porém apoiada em documentos gerados em etapas distintas da história da humanidade e por autores cuja formação básica, predileção científica e linha filosófica que não são as mesmas, a abordagem do assunto é ainda mais heterogênea.
É senso comum que os níveis de base estão no cerne de várias questões do mundo moderno, de forma ainda muito semelhante àquela que ocorria em um passado próximo ou até mesmo remoto. Os patamares morfoestruturais dos rios foram palco do surgimento de grandes civilizações, como o antigo Egito, e continuam motivando grandes aglomerações urbanas, como é o caso da cidade de São Paulo.

Se por um lado a topografia plana, fertilidade, navegabilidade, umidade, retenção e concentração de recursos minerais estão entre os principais fatores responsáveis pela atração do Homem pelos níveis de base, por outro existem fenômenos naturais como as inundações e o assoreamento que têm acarretado prejuízos incalculáveis aos povos que insistem em 
ocupar as porções marginais dos cursos d'água.

Com base no que foi exposto acima, é natural que pesquisas nos mais variados campos do conhecimento humano sejam desenvolvidas sobre os níveis de base e, justamente por essa diversidade de enfoques, a essência geológica dos fenômenos, que reside em questões anteriores à própria existência do Homem, seja ignorada ou interpretada de forma equivocada. Dentro deste contexto, uma revisão sobre o assunto, levando em conta vários momentos da evolução filosófica, técnica e científica da sociedade, pode ajudar a elucidar os diversos sentidos atribuídos ao conceito e, desta forma, tornar sua adoção mais apropriada aos estudos atuais.

\section{2 - Desenvolvimento Histórico e Filosófico do Conceito}

É atribuída a Heródoto, o pai da História, a frase: "O Egito é uma dádiva do Nilo". Nesta passagem, dita há mais de 400 anos antes de Cristo, fica clara a noção das relações existentes entre os processos de agradação fluvial nos níveis de base (deposição de sedimentos argilosos na planície de inundação, no período pós-cheias) e os demais elementos dos sistemas fluviais, incluindo aí a sociedade humana.

$\mathrm{Na}$ Grécia antiga, fenômenos como a permanência do fluxo d'água num rio, mesmo fora da época de chuvas aguçavam a curiosidade dos homens e estimulavam a busca de explicações. Foi a partir daí que surgiram as primeiras tentativas de racionalizar a natureza, usando como base princípios como o do tempo infinito, da existência da denudação e da conservação de massa.

A engenharia desenvolvida pelos romanos colaborou, na sequência, com a parte prática dos estudos da natureza. Seguindo esta época, a Idade Média contou com a atribuição inquestionável de todos os fenômenos naturais à ação de Deus, de forma que as obras gregas e romanas só viriam a ser resgatadas com o Renascimento.

A conversão dos sistemas fluviais em um tema científico é um provável resquício dos ideais renascentistas prevalecentes até meados dos anos 1650, quando a máxima era a reflexão de assuntos até então investigados exclusivamente sob a ótica eclesiástica.

Apesar de todo o esforço de ruptura com a forma de construção e transferência de conhecimento adotada durante a Idade Média, era inevitável que parte desses mecanismos ainda se perpetuasse por algum tempo junto à comunidade científica iluminista, influenciando sua tentativa de racionalizar o mundo (Descartes 1637).

Talvez por este fato as contribuições de Leonardo da Vinci sobre erosão e deposição fluvial, que culminaram na percepção da capacidade da água em continuamente "corroer" as montanhas e "encher" os vales, não tenham conseguido despertar o interesse por novas observações e idéias que viessem a melhorar a compreensão do papel dos níveis de base locais, fato destacado por Marques (2007).

No que diz respeito à dinâmica fluvial, esta influência se fez perceber nas teorias cataclismáticas que Bigarella (2003) descreve como comuns no início do século XVIII. Nesta fase, acreditava-se numa instalação catastrófica (divina?) de vales, ocupados pelos rios apenas em fases posteriores da evolução do relevo.

Ao longo do século XVIII, a abordagem catastrofista seria paulatinamente refutada, dando lugar ao atualismo de James Hutton que, cedendo bases para discussões e conclusões posteriores (p. ex. trabalhos de Charles Lyell, Albert Penck, Jean Louis Agassiz, John Wesley Powel e William Morris Davis), culminaria no paradigma atual, segundo o qual os rios esculpem seus próprios vales a partir de sua ação erosiva, governados pela variabilidade espacial e temporal dos níveis de base.

Segundo Howard et al. (1994), desde Hutton acredita-se que as paisagens são criadas por processos erosivos/deposicionais agindo sobre superfícies tectonicamente criadas. Os estudos do século XIX apontaram para interações entre tectônica e erosão devido à isostasia.

Até recentemente, essa interação foi amplamente separada nos estudos geológicos. Os geomorfólogos consideravam a deformação tectônica um obstáculo imposto pelos geodinamicistas, especificando-a como uma condição limite para a descarga erosiva nas montanhas e carga sedimentar nas bacias.

Apesar disso, a visão de interação entre os processos geomórficos e tectônicos é cada vez mais apreciada. Vários modelos de erosão regional têm sido baseados nela, apesar da maioria das modelagens supersimplificar os processos de erosão, transporte, deposição, além das influências do tectonismo, particularmente nos sistemas fluviais (Milliman e Syvitski, 1992).

Dentre os primeiros trabalhos científicos sobre sedimentologia e geomorfologia fluvial, destaca-se a investigação geométrica de leitos executada pelo geólogo britânico Sorby (1859). Neste trabalho, 
foram estudadas, dentre outros assuntos, as laminações geradas por ripples com o objetivo de, por analogia, serem compreendidos os condicionantes e mecanismo de deposição de areias constituintes de arenitos com mais de 300 M.a..

O estabelecimento do conceito de "nível de base" de erosão fluvial, do inglês fluvial erosion base level, entretanto, só apareceria no fim do século XIX, podendo ser atribuído a Powell (1875) (de acordo com Burbank e Anderson (2001), Christofoletti (1980), dentre outros). Ao contrário de Sorby (1859), neste caso o objetivo não era o estudo empírico do canal fluvial, mas sim a definição de leis que governam a dinâmica dos rios.

Powell (1875), no último parágrafo da página 173 de seu relatório sobre a exploração do rio Colorado (EUA) e afluentes, diz: "Quando uma grande dobra emerge em relação ao nível do mar, ou se eleva em relação ao nível de base de erosão, seu eixo aparece num primeiro momento acima do nível d'água (ou nível de base), sendo imediatamente atacado pelas chuvas e as areias dali carregadas vão formar novos depósitos."

Foi a partir deste conceito de nível de base que o princípio de denudação fluvial, associada ao "ciclo de erosão" (Davis, 1899), foi concebido. Este conceito seria lembrado e revisado, com algumas variações de interpretação, por autores como Penck (1953) e, apesar de sua característica sabidamente fixista, teve um papel fundamental na evolução dos conceitos geomorfológicos de evolução do relevo.

O ciclo de erosão "davisiano" engloba a série completa de mudanças ocorridas durante a longa evolução da paisagem, a partir da escavação fluvial. As três etapas sucessivas deste ciclo são acompanhadas de redução da declividade das vertentes e foram definidas em analogia às fases da vida, numa ordem decrescente de poder erosivo do canal fluvial, denominadas, respectivamente, como juventude, maturidade e senilidade.

A teoria de Penck (op. cit.), por sua vez, concebe um recuo paralelo das vertentes, sem que haja redução substancial em sua declividade (Fig. 1).

O ciclo de erosão é uma grande simplificação dos processos operantes ao longo do canal fluvial, da nascente à foz, uma vez que envolve uma abordagem em escala regional (Schumm 1991) e, principalmente, considera a crosta terrestre como uma entidade praticamente estática.

Entretanto, as teorias de vários autores como Davis e Penck para o recuo das vertentes, sistemas morfoclimáticos, formação de pediplanos e teste-
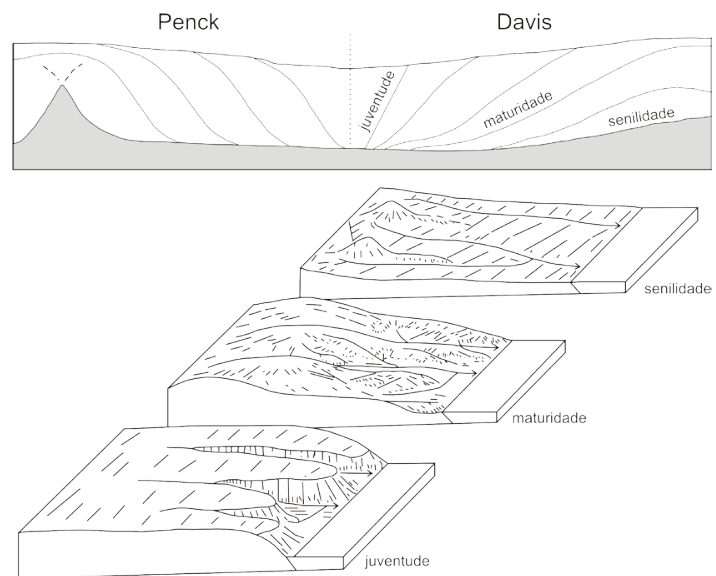

Figura 1. Ciclos de erosão, conforme a teoria do recuo paralelo das vertentes de Penck e a da redução progressiva da inclinação das encostas de Davis. Adaptado de Bigarella (2003) e Penteado (1978)

munhos de paleoclimas invariavelmente remetiam à importância dos níveis de base locais, fato que ajuda a impedir que suas idéias sejam totalmente desabonadas.

Nos anos cinquenta alguns autores já apontavam para os equívocos da teoria de Davis. Eles chamavam a atenção para o fato de que o ciclo de erosão nem sempre segue sua marcha sem interrupções, tendo em vista a possibilidade, por exemplo, de ocorrência de soerguimento em zonas de drenagem madura ou senil, ou até mesmo a sua invasão por glaciares.

Holmes (1952), entretanto, é categórico ao afirmar que os vales atuais, tanto na Grã-Bretanha, seu país de origem, quanto em outras partes do mundo apresentam as três etapas dos ciclos de erosão em atividade.

Afirmações como esta, ao serem seguidamente encontradas na literatura, refletem o fato de boa parte dos rios europeus e norte-americanos nascerem em importantes cadeias de montanhas (Apalaches, Rochosas, Alpes, Pirineus, etc.), se dirigindo diretamente ao nível de base global.

Posto que a divulgação científica, até os dias de hoje, passados mais de cinquenta anos, é dominada não só pela ótica, mas também pelo idioma anglo-saxônico, é natural que o ciclo de erosão de Davis tenha sido o modelo generalizado para os sistemas fluviais de todo o mundo.

Todos os princípios técnico-científicos derivados dessa abordagem, sobretudo aqueles que permeiam áreas do conhecimento para as quais o meio físico "pode" ser considerado uma entidade inerte e estática, reproduzem, à custa do desconhe- 
cimento de seus usuários finais, o mesmo equívoco de generalização.

No final do século XIX, Grove Karl Gilbert, de acordo com Marques (2007), teria estabelecido relações entre processos e resistência dos materiais à ação do modelado do relevo, criando uma noção do que se conhece hoje como "equilíbrio dinâmico".

Hershel (1837) apud Cannon (1961) propôs à Royal Society of London que o equilíbrio dinâmico entre os processos crustais e superficiais é mantido porque a crosta terrestre repousa sobre um material quente o suficiente para mantê-lo em estado "semi-fluido". Ele sugere que a redistribuição de massa na superfície ocorre como uma resposta à movimentação lateral em profundidade.

Conceitos advindos da teoria geral de sistemas, semelhantemente, contribuíram para a evolução do conhecimento geomorfológico, colaborando com a fixação do conceito de nível de base. Destacam-se aí a noção dos sistemas aberto e a noção de equilíbrio (Schumm 1977; Schumm 1991 e Nelson 1998).

Um rio hipoteticamente equilibrado, segundo Holmes (1952) apresentaria um gradiente inversamente proporcional ao caudal, ou seja, o perfil seria tanto mais abrupto, quanto mais próximo das cabeceiras, e isso levaria a uma forma côncava para cima (figura 2).

Este perfil de equilíbrio, totalmente liso, praticamente não é encontrado na natureza devido às influências dos níveis de base locais (Schumm 1977). Portanto, é plausível se referir a um perfil escalonado (graded profile), mais condizente com a realidade da maioria dos sistemas fluviais (figura 3).

O uso do conceito de equilíbrio dinâmico mostraria que as formas são resultado contínuo de um ajuste entre o comportamento dos processos e o nível de resistência oferecida pelo material que está sendo trabalhado (Tricart 1977). As formas deixam de ser algo estático. Daí surge a idéia de que o mesmo processo poderia originar várias formas diferentes, a depender da evolução temporal dos

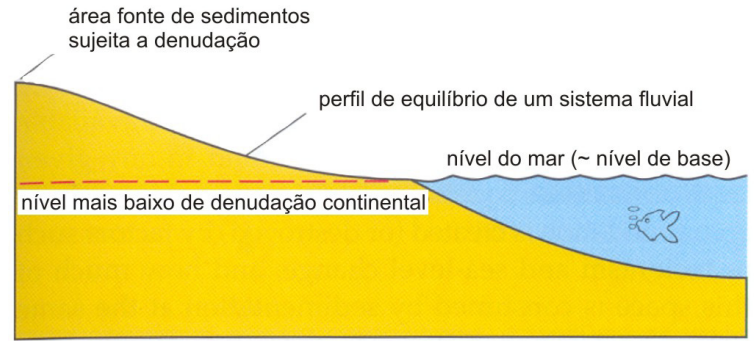

Figura 2. Perfil de um rio hipoteticamente equilibrado. Modificado de Catuneanu (2007)

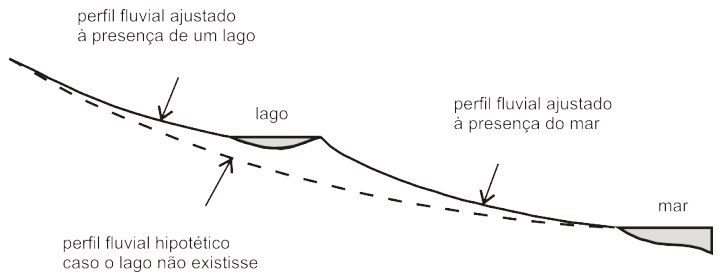

Figura 3. Perfil escalonado de um rio, em resposta à presença de níveis de base. Modificado de Catuneanu (2007).

níveis de base (Schumm 1977 e Schumm 1991).

Segundo Marques (2007) os processos geomórficos sofrem a influência de vários fatores e, desta forma, a previsibilidade dos sistemas geomorfológicos é pequena quando as variáveis são analisadas em conjunto.

Esse fato pode ser visto como um complicador da modelagem teórica matemática (p. ex. Julien 2002) ou puramente qualitativa das respostas do relevo, à medida que os canais fluviais se deparam com diferentes níveis de base no seu caminho em direção ao nível de base regional (ou global).

Vindo ao encontro destas idéias, segundo Dury (1970), ocorre o nascimento de uma geomorfologia com forte tendência à quantificação. Com ela, é aberto caminho para a morfometria, principalmente com os trabalhos de Robert Horton e Arthur Strahler das décadas de 1940 e 1950 (p. ex.: Horton 1945 e Strahler 1952), o que suscitaria o uso mais intenso da matemática e da estatística.

Na década de 1970, segundo Merrits e Ellis (1994), os geólogos cessam as discussões sobre a origem da paisagem, que vinham tomando sua atenção desde o século XIX. Tal fenômeno se deveu à consolidação da teoria da Tectônica de Placas, que operou como um denominador comum para várias teorias de conotação geológica ou geográfica sobre o papel dos rios na evolução do relevo.

Seguindo-se a isso, houve uma reunião entre a Geomorfologia e a Geologia que, entretanto, estabeleceram entre si uma relação muito sutil.

Os anos 80 foram marcados por sobreposições entre a sismologia, tectônica, climatologia e geomorfologia. Apesar disso, uma fusão verdadeira entre elas não ocorreu (Merrits e Ellis, op. cit.). Enquanto sismólogos e geofísicos trabalhavam com escalas locais e de curto tempo, climatólogos e geomorfólogos tectonicistas adotavam escalas regionais e de tempos mais longos. 


\section{3 - Definiç̧ões de Nível de Base Fluvial: Questionamentos e Aplicabilidade}

Tendo em vista a grande importância dos sistemas fluviais nos mais variados ramos das geociências, é natural que glossários geológicos, bem como livros-texto sobre Geologia Geral e Geomorfologia, além dos artigos de áreas correlatas, sempre tragam uma definição sumarizada para o termo nível de base.

Dentre as definições encontradas na literatura, podem-se listar alguns exemplos:

. Leinz e Mendes (1959): nível limite além do qual a ação erosiva das águas correntes não pode mais rebaixar uma região. Assim, o nível do mar ou o nível de um lago representam os níveis de base para os rios que neles desembocam.

. Holmes (1952): prolongamento imaginário do nível do mar abaixo do continente.

. Lange et al. (1963): nível no sopé de um talude, a partir do qual as ravinas crescem.

. Thornbury (1958): limite inferior de aprofundamento de um vale ou da erosão fluvial.

. Suguio (1992) e Suguio (2003): limite topográfico, abaixo do qual uma drenagem não consegue erodir o continente, representando o estado de equilíbrio num dado momento entre a deposição e erosão. É também conhecido como nível de base de erosão.

. Shanley e McCabe (1994): nível mais baixo ao qual a erosão da superfície da Terra busca atingir. É especialmente o nível abaixo do qual os rios não conseguem erodir seus depósitos.

. Allaby e Allaby (1999): superfície plana teórica que envolve uma massa continental, denotando a profundidade abaixo da qual a erosão estaria incapaz de ocorrer.

. Burbank e Anderson (2001): limite mais baixo da paisagem, abaixo do qual os rios não podem erodir.

. de Blij et al. (2004): nível abaixo do qual um rio não pode erodir seu leito.

. Press et al. (2006): elevação na qual um rio termina desembocando em um grande corpo de água parada, tal como um lago ou oceano.

. Cunha (2007): entidades originadas a partir de controles, na maioria estruturais, que seccionam o curso d'água em segmentos individualizados com perfis de equilíbrio próprios, modificando a visão teórica do perfil longitudinal de rios.

Como se pode perceber, a maior parte das definições listadas converge para "um nível no qual os fenômenos fluviais de erosão e transporte dão lugar aos deposicionais”. Entretanto, algumas variações sutis podem ser percebidas. Neste caso, para evitar qualquer equívoco de interpretação, a terminologia mais descritiva e, portanto, adequada para nível de base seria "nível de base geomórfico" (geomorphic base level) (termo adotado por Shanley e McCabe, 1994).

Muitos autores trabalham com a diferenciação entre um nível de base final ou global (ultimate base level) (figura 2) e níveis de base locais (local base levels) (figura 3). Para Powel (1875), p.ex., existe uma diferenciação entre os níveis de base e patamares de expressão local.

Legenda

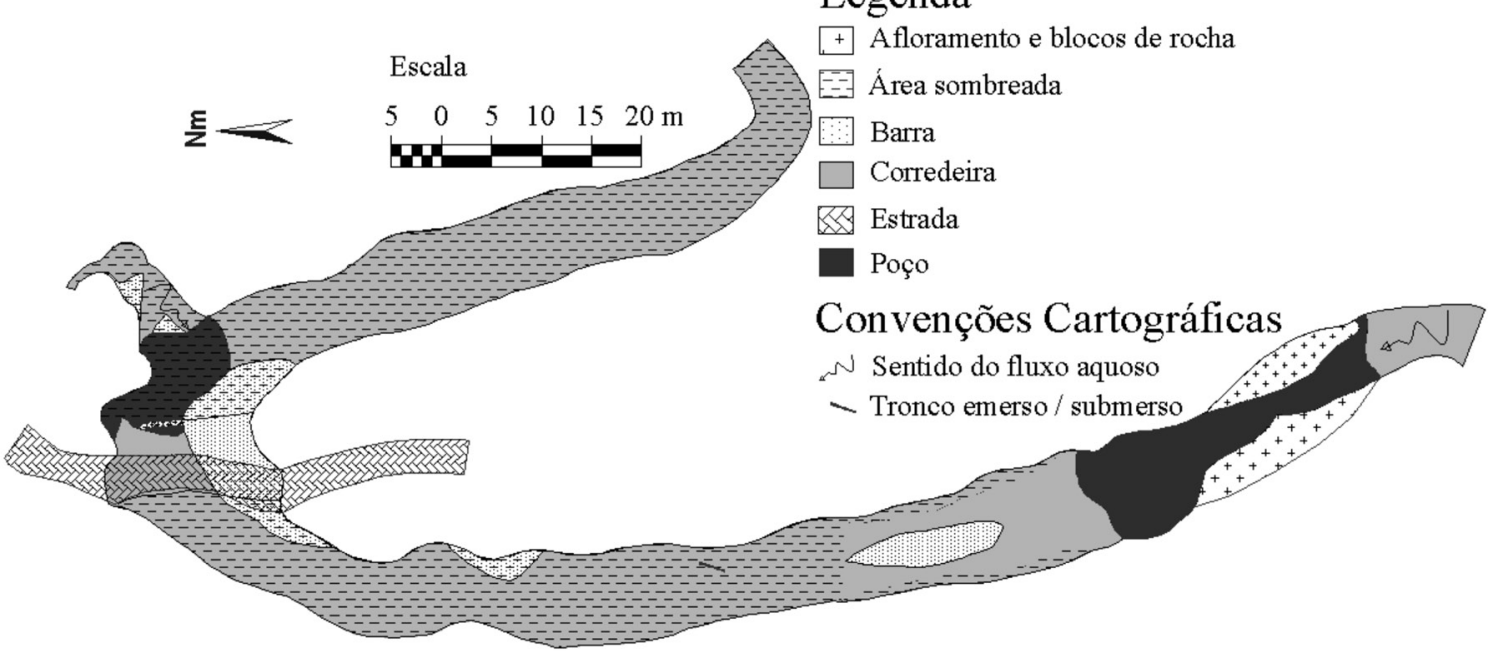

Figura 4 . Duas configurações para knickpoints (1) e suas possíveis posições futuras (2). 0 processo de instalação da quebra de patamar é mais rápido na área de cascata ("a") do que no segmento de corredeira sobre rochas in situ ("b"). Adaptado a partir de Schumm (2005). 
Em inglês, os limites desses níveis são denominados knickpoints ("pontos de inflexão" ou, conforme Bigarella (2003), "rupturas de declive" ou "rupturas de gradiente"). Apesar de seu caráter descritivo, na maioria das vezes o termo é aplicado a uma variação de declividade em escala espacial pequena, no nível dos segmentos fluviais (Burbank e Anderson 2001; Allaby e Allaby 1999; Severiano-Ribeiro 2001; dentre outros).

Segundo Allaby e Allaby (op. cit.), o knickpoint é também conhecido na literatura inglesa por headcut, sobretudo quando ocorre de forma abrupta. Ele separa segmentos normalmente côncavos para cima e ocorre frequentemente associado a um rebaixamento no nível de base ou, alternativamente, a variações no tipo de rocha ou no volume da descarga, ou até mesmo a confluência de um novo tributário (figura 4).

A instalação dos knickpoints altera o estado de equilíbrio anterior dos sistemas fluviais e sua ocorrência, dependendo das variáveis de controle, pode levar todo o sistema a outro estado de equilíbrio (Huggett 2003).

O nível do mar, para vários autores (p.ex.: Burbank e Anderson 2001; Suguio 2003; Severiano-Ribeiro 2001; dentre outros), equivaleria ao nível de base final, enquanto zonas pontuais de topografia deprimida seriam níveis de base locais, podendo consistir, por exemplo, de um lago (figuras 2 e 3 ).

Além disso, alguns autores trabalham com o conceito de "nível de base de erosão", que envolve todos os segmentos de um sistema fluvial. Ele consiste, segundo Bull (1991), de um perfil longitudinal escalonado em equilibrio, abaixo do qual um rio não é capaz de dissecar e no qual não podem ocorrer os processos de erosão e deposição. Para muitos autores, o termo não passa de um sinônimo de nível de base geomórfico.

Existem ainda outras variantes como o "nível de base de corrosão" (Suguio, 2003), aplicado ao plano até o qual o ciclo cárstico é capaz de se desenvolver, ou seja, o nível freático; além do "nível de base de deposição", que representa o nível máximo onde os depósitos sedimentares podem ser empilhados numa bacia (em sedimentos marinhos, equivale ao nível de base final) (figura 5).

Segundo Severiano-Ribeiro (2001), merece menção o "nível de base estratigráfico", que seria a superfície em direção à qual os sistemas estratigráficos buscam se ajustar, por intermédio de sedimentação e preservação estratigráfica ou por bypass sedimentar ou ainda erosão dos depósitos. Em outras palavras, trata-se de um conceito mais dinâmico do que o "nível de base geomórfico", variando de acordo com a situação deposicional.

Apesar de o senso geral apontar para um nível de base final coincidente com o nível do mar, é importante destacar que várias exceções podem ocorrer.

Burbank e Anderson (2001) chamam a atenção para as depressões tectonicamente fechadas, como é o caso do Vale da Morte (EUA), que configura um nível de base final inferior ao nível do mar. O Mar Morto (Jordânia, Israel e Cisjordânia), dentro deste contexto, também se comporta como o nível de base final do rio Jordão.

O oposto também ocorre em casos como, por exemplo, o do deserto de Atacama, no Chile, ou do Lago Titicaca (Peru), no topo da cordilheira dos Andes. Este último, a quase $4 \mathrm{~km}$ acima do nível do mar. Enquadram-se aí situações como a do rio Okawango, cuja desembocadura ocorre na forma de um delta interior, ou seja, o nível de base final neste caso está no deserto do Kalahari, em Botswana, cerca de $950 \mathrm{~m}$ acima do nível do mar (Gumbricht et al. 2001).

\section{4 - Agradecimentos}

Os autores agradecem à Fundação de Amparo à Pesquisa de Minas Gerais (Fapemig), à Coordenação de Pessoal de Nível Superior (Capes), ao Departamento de Geologia da UFOP e ao Departamento de Geologia da UFES.
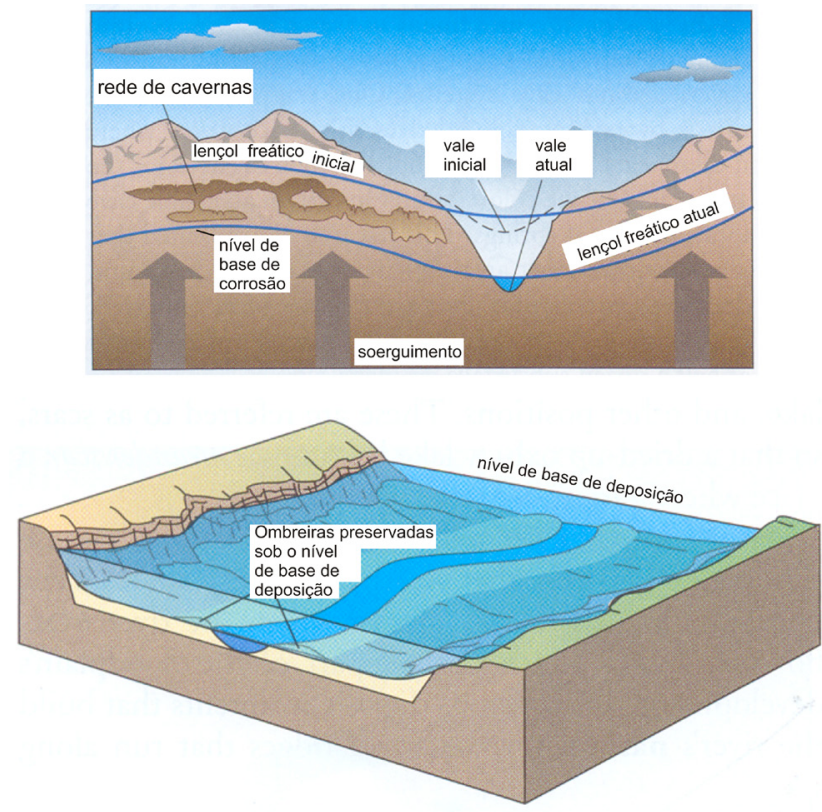

Figura 5. llustrações dos níveis de base de corrosão e de deposição. Modificado de de Blij et al. (2004). 


\section{Referências Bibliográficas}

Allaby A., Allaby M. 1999. Dictionary of Earth Sciences. Grã-Bretanha: Oxford. 619p.

Bigarella J.J. 2003. Estrutura e origem das paisagens tropicais e subtropicais, vol. III - Processos erosivos, vertentes, movimentos de massa, atividade endógena, superfícies de erosão, compartimentação do relevo, depósitos correlativos e ambientes fluviais. Florianópolis: Editora da UFSC. 559p.

Bull W.B. 1991. Geomorphic Responses to Climatic Change. Londres: Oxford. 326p.

Burbank D.W., Anderson R.S. 2001. Tectonic Geomorphology. EUA: Blackwell. 274p.

Cannon W.F. The Impact of Uniformitarianism: Two Letters from John Herschel to Charles Lyell, 1836-1837. Proceedings of the American Philosophical Society. 105(3):301-314.

Catuneanu O. 2007. Principles of Sequence Stratigraphy. China: Elsevier. 375p.

Christofoletti A. 1980. Geomorfologia. São Paulo: Edgard Blücher. 188p.

Cunha S.B. 2007. Geomorfologia Fluvial. In: Guerra A.J.T., Cunha S.B. eds. 2007. Geomorfologia - Uma Atualização de Bases e Conceitos. Rio de Janeiro: Bertrand Brasil. p. 211-252.

Davis W.M. 1899. The Geographical Cycle. Geographical Journal. 14:481-504.

De Blij H.J., Muller P.O., Williams Jr. R.S. 2004. Physical Geography - The Global Environment. EUA: Oxford. 702p.

Descartes R. 1637. Discurso do Método. Porto Alegre: L\&PM. 128p.

Dury G.H. (ed.). 1970. River and River Terraces. Londres: MacMillan. 283p.

Gumbricht T., McCarthy T.S. Merry C.L. 2001. The topography of the Okavango Delta, Botswana, and its tectonic and sedimentological implications. South African Journal of Geology, 104:243-264.

Holmes A. 1952. Principles of Physical Geology. London: Nelson. 512p.

Horton R.E. 1945. Erosinal development of streams and their drainage basin: hydrophysical approach to quantitative morphology. Geol. Soc. America Bulletin, 56(3):275-370.

Howard A.D., Dietrich W.E., Seidl M.A. 1994. Modeling Fluvial Erosion on Regional to Continental Scales. Journal of Geophysical Research, 99(B7):13.971-13.986.

Huggett R.J. 2003. Fundamentals of Geomorphology. Grã-Bretanha: Routledge. 386p.

Julien P. 2002. River Mechanics. EUA: Cambridge. $434 \mathrm{p}$.

Lana C.E. 2004. Cartografia Integrada de Ecossistemas Lóticos (Fluviais) no Alto Curso do Rio das Velhas - MG. Ouro Preto: Depto. Geol. Ufop. 185p. (Dissert. Mestrado).
Lange O., Ivanova M., Lebedeva N. 1963. General Geology. Moscou: Foreign Languages Publishing House. 202p.

Leinz V., Mendes J.C. 1959. Vocabulário Geológico. São Paulo: Companhia Editora Nacional. 180p.

Marques J.S. 2007. Ciência Geomorfológica. In: Guerra A.J.T. e Cunha S.B. eds. 2007. Geomorfologia - Uma Atualização de Bases e Conceitos. Rio de Janeiro: Bertrand Brasil. p. 23-50.

Merrits D.J., Ellis M. 1994. Introduction to Special Section on Tectonics and Topography. Journal of Geophysical Research, 99(B6):12.135-12.141.

Milliman J.D., Syvitski J.P.M. 1992. Geomorphic/ Tectonic Control of Sediment Discharge to the Ocean: The Importance of Small Mountainous Rivers. The Journal of Geology, 100:525-544.

Nelson M. 1998. Hidrology and the River Environment. Grã-Bretanha: Oxford. 221p.

Penck W. 1953. Morphological Analysis of Landforms. Londres: McMillan. 429p.

Penteado M.M. 1978. Fundamentos de Geomorfologia. Rio de janeiro: IBGE. 180p.

Powell J.W. 1875. Exploration of the Colorado river of the west and its tributaries. Washington: Washington D.C. U.S. Govt. Printing Office. 291p. URL: $<$ http://quod.lib.umich.edu/cgi/t/text/text-idx? $\mathrm{c}=\mathrm{moa} ; \mathrm{cc}=$ moa $; \mathrm{rgn}=$ main $; \mathrm{view}=$ text $; \mathrm{idno}=\mathrm{A}$ FK4571.0001.001> Acesso: 07/09/2008.

Press F., Siever R., Grotzinger J, Jordan T.H. 2006. Para Entender a Terra. Porto Alegre: Bookman. 656p.

Schumm S.A. 1977. The Fluvial System. Nova Iorque: Wiley. 338p.

Schumm S.A. 1991. To Interpret Earth - Ten Ways to be Wrong. Grã-Bretanha: Cambridge. 133p.

Schumm S.A. 2005. River Variability and Complexity. Grã-Bretanha: Cambridge. 234p.

Severiano-Ribeiro H.J.P. 2001. Estratigrafia de Seqüências: Fundamentos e Aplicações. São Leopoldo: Unisinos. 428p.

Shanley K.W. e McCabe P.J. 1994. Perspectives on Sequence Stratigraphy of Continental Strata. Am. Assoc. Petr. Geol. Bull., 78(4):544-568.

Sorby, H. C. 1859 . On the structures produced by the currents during the deposition of stratified rocks. Geologist, 2:137-147.

Strahler A.N. 1952. Hypsometric (area-altitude) analysis and erosional topography. Geol. Soc. Am. Bull., 63:1117-1142.

Suguio K. 1992. Dicionário de Geologia Marinha (com termos correspondentes em inglês, francês e espanhol). São Paulo: T. A. Queiroz. 171p.

Suguio K. 2003. Geologia Sedimentar. São Paulo: Edgard Blücher. 400p.

Thornbury W.D. 1958. Principles of Geomorphology. Londres: Chapman \& Hall. 618p.

Tricart J. 1977. Ecodinâmica. Rio de Janeiro: IBGE. 91p. 